\title{
OS FASCISMOS ITALIANO E ALEMÃO - BASES SOCIAIS E IDEOLÓGICAS E DINÂMICA GEOPOLÍTICA
}

Resumo: A partir de uma problematização da categoria de fascismo "clássico" que aponta para a necessidade de apreensão dos contextos históricos concretos em que se realiza a forma fascista de Estado, o artigo propõe analisar as características do fascismo nas formações sociais italiana e alemã do início do século XX. Pondo em destaque as complexas relações entre os elementos da estrutura social e ideológica presentes em cada uma destas formações sociais, bem como os efeitos geopolíticos que destas relações emerge, o artigo sustenta a tese de que os fascismos italiano e alemão assumiram respectivamente as formas concretas do fascismo débil ou elástico e do fascismo totalitário. Ao final, o artigo esboça um breve resumo da forma assumida pela luta antifascista na formação social italiana, marco das chamadas frentes populares e da democratização a partir de baixo das lutas contra o fascismo, bem como do papel militar que aí cumpriu, a partir da frente Leste, a URSS. A metodologia utilizada é a da pesquisa bibliográfica.

Palavras chave: Fascismo débil. Fascismo totalitário. Itália. Alemanha.

\section{THE ITALIAN AND GERMAN FASCISMS - SOCIAL AND IDEOLOGICAL BASES AND GEOPOLITICAL DYNAMICS}

Abstract: From a problematization of the category of "classical" fascism that points to the awareness of the concrete contexts in which a state fascism takes place, the article proposes the analysis of the characteristics of fascism in the Italian and German social formations in the beginning of the twentieth century. By emphasizing the complex relations between the elements of the social and ideological structure present in each of these social formations, as well as the geopolitical effects of these relations, the article sustains the thesis that Italian and German fascisms respectively assumed the concrete forms of weak or elastic fascism and totalitarian fascism. Finally, the article outlines a brief summary of the form assumed by the antifascist struggle in the Italian social formation, a landmark of the so-called popular fronts and of democratization from below the struggles against fascism, as well as the military role that it fulfilled from the east front, the USSR. The methodology used is that of bibliographic research.

Key words: Weak fascism. Totalitarian fascism. Italy. Germany.

\section{LOS FASCISMOS ITALIANO Y ALEMÁN - BASES SOCIALES E IDEOLÓGICOS Y DINÁMICA GEOPOLÍTICA}

Resumen: A partir de una problematización de la categoría de fascismo "clásico" que apunta a la necesidad de aprehensión de los contextos históricos concretos en que se realiza la forma fascista de Estado, el artículo propone analizar las características del fascismo en las formaciones sociales italiana y alemana del inicio

1 Universidade Federal de Santa Catarina, Departamento de Geociências, Florianópolis, Brasil, maurelio@cfh.ufsc.br, https://orcid.org/0000-0002-2228-9664 
del proceso, siglo XX. En cuanto a las complejas relaciones entre los elementos de la estructura social e ideológica presentes en cada una de estas formaciones sociales, así como los efectos geopolíticos que de estas relaciones emerge, el artículo sostiene la tesis de que los fascismos italiano y alemán asumieron respectivamente las formas concretas del fascismo débil o elástico y del fascismo totalitario. Al final, el artículo esboza un breve resumen de la forma asumida por la lucha antifascista en la formación social italiana, marco de las llamadas frentes populares y de la democratización desde abajo de las luchas contra el fascismo, así como del papel militar que allí cumplió, desde el frente Este, la URSS. La metodología utilizada es la de investigación bibliográfica.

Palabras clave: Fascismo débil. Fascismo totalitário. Italia. Alemania.

\section{Introdução}

A discussão sobre os fascismos italiano e alemão, que se desenvolveram na Europa da primeira metade do século XX, não pode ser feita sem que antes se trate, ainda que sob a forma de uma introdução, da categoria de fascismo "clássico". Foi Palmiro Togliatti (1964), dirigente ao lado de Gramsci no Partido Comunista Italiano (PCI), quem assinalou pela primeira vez, em um artigo de abril de 1931, preparado para uma intervenção em uma reunião do Comitê Executivo da Internacional Comunista (IC), os problemas do uso indiscriminado desta categoria; um uso que parecia então se difundir com facilidade e que se ligava à definição mesmo do que seria o fascismo e à periodização do seu desenvolvimento. Assim é que, por exemplo, o geógrafo e marxista Karl Wittfogel, partindo de um elogio de Mussolini ao socialista alemão Kurt Eisner, terminava por concluir ser Eisner, e sua formulação em torno de um programa de "reforma social" de tipo pequeno burguês, o pai espiritual de Mussolini e do fascismo italiano. Pondo-se em desacordo com esta conclusão, ela mesma o ponto de afirmação da identidade entre os fascismos alemão e italiano, Togliatti irá insistir que o artigo de Mussolini, como costuma ocorrer com todo "regateador da cultura", era apenas a reunião, bastante incoerente, das mais diferentes doutrinas - "Sorel, Pareto, Croce, Gentile e até Lênin e Trotski" -, não podendo, portanto, servir como uma referência realmente válida para uma comparação entre as duas formações (TOGLIATTI, 1964, p. 65).

Mas no centro do debate sustentado por Togliatti não estão nem Eisner e nem tampouco Wittfogel. Em sua intervenção Togliatti alveja na verdade Leon Trotsky, que já está fora da URSS e em aberta oposição à linha política dominante na IC. Para o dirigente político italiano, ao aceitar partir da idéia do "fascismo italiano como fascismo “clássico'”, Trotsky “terminava por concluir” como "obrigatória”, reproduzível 
em todos os casos e países, "a linha de desenvolvimento" seguida pelo fascismo italiano (TOGLIATTI, 1964, p. 68-69). Daí sua espera de uma nova marcha sobre Roma, com o papel que nela cumpriu a pequena burguesia, para que se pudesse concluir acerca da presença do fascismo na Alemanha; coisa que, na interpretação de Togliatti, já existia desde pelo menos a crise de 1929, se não sob a forma de uma ditadura, mas de uma política de governo seguida pela própria social-democracia. Conforme escreveu o autor italiano, "o movimento da pequena burguesia e das camadas de deslocados que formam a base de massa das organizações fascistas não pode ser considerado como um elemento independente" ou mesmo "determinante da marcha do fascismo", já que esta determinação deveria ser buscada no "grande capital financeiro" e nos "estratos dirigentes da burguesia" (TOGLIATTI, 1964, p. 69).

Não é o lugar aqui para entrar no debate entre Togliatti e Trotsky e, de modo mais geral, entre Trotsky e a IC - o que será feito en passant no desenvolvimento do artigo - cabendo apenas, nesta introdução geral ao tema, o registro de que, a rigor, Trotsky não parece negligenciar o papel do grande capital financeiro. É o que se vê por suas referências, em um artigo de 1930, de que a "grande burguesia" - verbi gratia, "o capital financeiro" - não pode se "manter no poder se não tem o apoio da pequena burguesia das cidades e do campo", apoio que "assume, na época atual, duas formas principais", "antagônicas", mas que "se complementam: a socialdemocracia e o fascismo" (TROTSKY, 2018, p. 31). Além disso, é preciso não esquecer que a ênfase de Togliatti no capital financeiro seguia muito de perto a fórmula da IC e a problemática teoria do social-fascismo, um tanto esquecida da "advertência de Marx contra o esquematismo de uma visão reduzida da sociedade como uma única e indiferenciada 'massa reacionária'" (LOSURDO, 2006, p. 190).

De qualquer modo, do ponto de vista teórico-metodológico, resta válida a advertência de Togliatti, insistindo que o "processo de facistização do Estado burguês não é um processo abstrato, mas histórico", devendo ser analisado segundo "as condições do período em que ele se desenvolve" e segundo "a situação objetiva do país" em que ele aparece (TOGLIATTI, 1964, p. 66). É, com efeito, esta advertência teórico-metodológica que será tomada aqui para recortar as diferenças entre os fascismos que se desenvolvem na formação social alemã e italiana na Europa da primeira metade do século XX.

Este artigo tem por objetivo geral apreender os contextos históricos concretos em que se realizou o fascismo nas formações sociais da Itália e Alemanha do início 
do século XX. Além desta introdução e das conclusões, ele se divide em duas grandes seções e suas subdivisões: 1. Quadro geral do fascismo italiano; 1.2. O fascismo como polícia econômica; 1.3. A geopolítica de um imperialismo fraco; 2. A forma totalitária alemã; 2.1. As bases sociais e ideológicas; 2.2. A geopolítica do fascismo totalitário. A metodologia empregada é a da pesquisa bibliográfica.

\section{Quadro geral do fascismo italiano}

O fascismo, assinalou Gianni Fresu (2017), nasce em um contexto econômico e geopolítico bem preciso. São os anos do apogeu da II Revolução Industrial, da centralização de capitais, do imperialismo e das conquistas territoriais. Do ponto de vista social, são os anos da afirmação da classe operária, um processo não destituído de limites, como se vê pela força do anarquismo italiano e francês, assim como pelo reformismo do movimento operário inglês e alemão.

Ainda para Fresu (2017), uma das interpretações mais originais e completas do fascismo, vale dizer, capaz de observar este fenômeno histórico-político por todos os seus ângulos, foi aquela fornecida por Antonio Gramsci. Mais que qualquer outra, sua leitura ultrapassa os limites das tantas interpretações liberais, seja aquelas que se desenvolveram enquanto o movimento fascista ganhava corpo na Europa, seja aquelas que se estabeleceram após a derrota do fascismo.

Inclinando-se a uma leitura abertamente reacionária, as interpretações liberais buscavam apresentar o fascismo como um simples parêntese da história européia, sempre insistindo na perda de consciência e na crise moral provocada pela guerra, ou mesmo nas mobilizações de massa e na vitória do bolchevismo; a primeira uma tese fundamentalmente sustentada pelo filósofo italiano Benedetto Croce, mas que teve muitos ecos fora da Itália; a segunda uma expressão da historiografia alemã liderada sobretudo por Ernest Nolte, e que se desenvolveu amplamente em toda a Europa após a II Guerra Mundial (FRESU, 2017).

De fato, Gramsci não despreza os elementos ideológicos expostos pela crise moral da burguesia européia, mas uma vez apoiado no materialismo histórico, ressalta antes de tudo as relações destes elementos com aqueles de natureza econômica como a constituição tardia, incompleta e bastante frágil do capitalismo financeiro italiano -, bem como social e política.

No que diz respeito a estes últimos, caberia dar atenção a engenhos institucionais como o Estatuto Albertino. Foi por meio dele que se forjou na Itália um 
ordenamento parlamentar cujo resultando fora uma forte união entre o rei e o legislativo, a qual terminava por entregar ao primeiro amplos poderes, como por exemplo a nomeação de ministros e até a dissolução do Parlamento (FRESU, 2017). Basta lembrar, a este respeito, que após a encenação da marcha sobre Roma, foi justamente o rei Vítor Emanuel III quem nomeou Benito Mussolini chefe de governo, decisão que não encontrou contestação suficiente entre as forças legislativas, completamente dominadas pela cultura transformista (FRESU, 2017), vale dizer, já entregue à "absorção gradual" e "contínua" junto aos quadros das classes dirigentes (GRAMSCI, 1975, Q 19, § 24, p. 2011). Um típico efeito de uma revolução burguesa que fora antes de tudo uma revolução-restauração, ou ainda uma revolução sem revolução, uma revolução passiva, realizada nas "formas e com meios que se pode chamar de 'liberais', ou seja, 'através da iniciativa individual, 'molecular', 'privada”, e não por "um programa de partido" e "segundo um plano prévio de ação prática e organizativa" (GRAMSCI, 1975, Q 19, § 24, p. 2011).²

$\mathrm{Na}$ interpretação de Gramsci, é precisamente a leitura liberal de Benedetto Croce, bastante negligente quanto aos efeitos de uma revolução burguesa conduzida pelo alto, que deve ser criticada se se desejar reter um ponto central do fascismo. Enquanto Croce sustenta que o regime fascista não é expressão de uma única classe, aparecendo, a rigor, em todas as classes, Gramsci enfatiza antes de tudo o papel das camadas médias - um ponto, como se vê, a aproximar Trotsky e Gramsci, o que, todavia, deve ser tomado cum grano salis, a ver os caminhos políticos claramente opostos seguidos por estes autores, como demonstrou a crítica recente do historiador Ruggero Giacomini a uma linha argumentativa iniciada por Angelo Tasca (GIACOMINI, 2014, p. 200-201). ${ }^{3}$

É precisamente da ênfase nos setores médios, nos recorda Fresu (2017), que parte a original contribuição de Gramsci, qual seja, a de que o fascismo não era apenas um regime de coerção, mas um regime que se apoiava simultaneamente na coerção e no consenso, os dois núcleos centrais do conceito de hegemonia. E é

\footnotetext{
2 Para uma melhor orientação dos leitores, na referência à edição crítica dos Cadernos do Cárcere, iremos citar, além do ano e da página, o caderno $(Q)$ e o respectivo parágrafo (§).

${ }^{3}$ Giacomini põe sob análise a leitura distorcida que no ano da morte de Gramsci (1937) faz Angelo Tasca (então em Moscou como representante do PCI para copiar documentos) da carta enviada pelo sardo, no ano de 1926, a Bukharin, autoridade máxima da IC. Trata-se da crítica à tese de que Gramsci aparecia em desacordo com a direção staliniana no que diz respeito à possibilidade de construção do socialismo na URSS sem uma revolução no Ocidente, uma tese considerada por Stalin, em crítica direta a Trotsky, como social-democrata (GIACOMINI, 2014, p. 200-201, 343). Com efeito, referindo-se ao Partido Comunista da Alemanha, Trotsky irá escrever em 1930: "é indispensável depurar o próprio partido do nacional-socialismo, cujo elemento essencial é a teoria do socialismo num só país" (TROTSKY, 2018, p. 50). Esta questão, não destituída de fortes relações com a temática deste artigo, reaparece nas nossas conclusões.
} 
assim que se pode compreender os esforços do regime para absorver toda uma camada de estudantes inadaptados, de oficiais de guerra sem função social, de pequeno-burgueses em vias de proletarização - o que geralmente foi feito utilizando o mito da "vitória mutilada" enunciado pelo poeta Gabriele D'Annunzio, ele que explorava a recusa dos Estados Unidos às aspirações italianas na Península Balcânica e na África após o fim da Primeira Guerra Mundial.

Primeiro chefe do intervencionismo, é de D'Annunzio que Mussolini empresta a retórica, as poses teatrais, as liturgias funerais e militares, a iconografia e até as palavras de ordem, todos meios para mobilizar e disciplinar a base de consenso do regime. Daí as relações entre consenso e militarismo, o último o eixo central do fascismo, mas também o seu verdadeiro ponto de chegada, a saber, uma geopolítica agressiva, inscrita em uma política externa abertamente imperialista (FRESU, 2017). No que diz respeito ao consenso, é preciso notar que este servia também à absorção do operariado no Estado burguês, notadamente por meio da assimilação dos organismos da sociedade civil por esta classe forjada, como no caso das instituições corporativas, surgidas já na década de 1920.

E é aqui que somos convidados a refletir criticamente acerca da tese predominante na IC no período de 1928-34 - o chamado terceiro período, preso à teoria do social-fascismo -, uma tese geralmente associada à "estratégia ZinovievStalin" (TROTSKY, 2018, p. 45), mas que na verdade esta ligada ao nome da principal liderança do Partido Comunista da Alemanha, Ernst Thälmann, "o primeiro a falar expressamente de fascistização da social-democracia e o mais explícito em indicar o reformismo, não o fascismo, como o pior inimigo dos comunistas" (FRESU, 2017, p. 180). De fato, como indicava já a linha dominante no interior do $\mathrm{PCl}$ desde que o grupo de Gramsci tem a hegemonia, o fascismo, mais do que simples expressão das mudanças na socialdemocracia, encerrava um quadro bem mais complexo. Típico movimento que assentava suas bases nas camadas médias sobressaltadas pelo contexto social e político, o fascismo se apresentava como uma "ideologia sem ideologia" e, nesse sentido, não surpreende que recolhesse as mais diferentes e até contraditórias doutrinas (FRESU, 2017).

De fato, recolhia não apenas (1) D'Annunzio e a disposição para a guerra; mas também (2) o irracionalismo e o futurismo de Marinetti, com seu nilismo de aparência inovadora, defensor de um débil programa liberal (FRESU, 2017), uma espécie de "romantismo contemporâneo" (GRAMSCl, 1975, Q 19, § 26, p. 2038) ou "modernizante", de "apelo frenético" ao "futuro" em nome da "liberdade individual", 
mas sempre movido por uma rebelião "romântica, avidamente espontânea" (PEDROSA, 2000, p. 213-214); (3) os economistas nacionalistas e sua ênfase nas corporações como forma de superar o conflito social; e em especial (4) o nacionalismo de Enrico Corradini e a tese da luta entre nações proletárias e capitalistas, premissa para o emprego da trágica teoria do Lebensraum, ou "espaço vital" (FRESU, 2017), maturada pela pena do geógrafo Friedrich Ratzel na Alemanha bismarkiana, o mesmo Ratzel que serviu de inspiração seja para o marxismo vulgarizado da II Internacional capaz de sustentar a guerra e o colonialismo -, seja para a escola de geopolítica alemã, expansionista e racista (LACOSTE, 1988, ROBERTO MORAES, 1991, LOSURDO, 1998). ${ }^{4}$

Ideologia sem ideologia, compreende-se que a verdadeira força motriz a guiar as massas no fascismo não fosse exatamente a razão, mas "o sentimento e a emoção", e para os quais, até mesmo "mais do que os discursos", contavam as "imagens" e os "monumentos", frequentemente referidos a uma romanidade idealizada, cujos "símbolos e ritos eram, junto a outros, o instrumento mais eficaz para dar uma alma às massas, enquadrando-as na política" (GIARDINA, 2008, p. 71). Mas aqui o papel principal coube mesmo ao corporativismo, a alternativa com a qual o fascismo se apresentou diante do fordismo e do americanismo.

\section{2 - O fascismo como "polícia econômica"}

É interessante observar que o fascismo se apresenta às classes dominantes italianas como uma alternativa ao fordismo americano. Estamos também aqui diante de uma expressão da revolução passiva, não há dúvida, mas exatamente na medida em que ela é uma forma pela qual a sociedade moderna encontra meios de se realizar sem remover todos os traços do passado, reelaborando-os para o novo contexto das sociedades de massa.

Recordemos o que escreveu Gramsci a esse respeito. Os métodos de Ford são o "ponto extremo de sucessivas tentativas da indústria no sentido de superar a lei tendencial da queda da taxa de lucro", e implicam em "uma forma de consumo da força de trabalho e uma quantidade de força consumida no mesmo tempo médio",

${ }^{4}$ Robert Moraes assinala que Ratzel, embora apoiado no positivismo, contrapunha-se às "teorias racistas que definem diferenciações de base no interior da humanidade" (ROBERT MORAES, 1991, p. 20). Segundo Domenico Losurdo, após ter viajado aos EUA no final do século XIX, o geógrafo alemão prevê e mesmo pressente ("un auspicio di funesta lucidità') que a derrota política e cultural dos abolicionistas norte-americanos fará sentir os seus efeitos bem além dos EUA, e na "Europa mais ainda que na Ásia" (LOSURDO, 2015, p. 301-302). 
que são os "mais gravosos e extenuantes" (GRAMSCI, 1975, Q 22 § 13, p. 2173). E é exatamente por isso que estes métodos são acompanhados de altos salários, o "instrumento para selecionar os trabalhadores qualificados adaptados ao sistema de produção e de trabalho e para mantê-los de modo estável" (GRAMSCI, 1975, Q 22, $\S 1$, p. 2140).

Ora, no velho continente, e em especial na Itália, nada disso se apresenta. Estamos diante da "velha e anacrônica estrutura social-demográfica européia", tão bem encarnada na zona meridional italiana, a qual Gramsci, inspirado nas observações de Goethe, chamou de o "mistério de Nápoles":

\begin{abstract}
Nápoles é a cidade onde a maior parte dos proprietários rurais do Mezzogiorno (nobres e não nobres) gasta sua renda da terra. Em torno de algumas dezenas de milhares destas famílias de proprietários, de maior ou menor importância econômica, com suas cortes de servos e lacaios imediatos, se organiza a vida prática de uma parcela significativa da cidade, com suas indústrias artesanais, com suas profissões ambulantes, com a enorme pulverização da oferta imediata de mercadorias e serviços aos desocupados que circulam pelas ruas. Outra parte importante da cidade se organiza em torno do transporte e do comércio atacadista. A indústria "produtiva", no sentido de que cria e acumula novos bens, é relativamente pequena, embora nas estatísticas oficiais Nápoles seja incluída como a quarta cidade industrial da Itália, depois de Milão, Turim e Gênova (GRAMSCI, 1975, Q. 22, § 2, p. 2142).
\end{abstract}

Por outras palavras, o que na Itália se observava não era mais que a "iniciativa superficial e macaqueadora dos elementos que começam a se sentir socialmente deslocados", expressão de "quem é impotente para reconstruir e toma como ponto de apoio os aspectos negativos da transformação" (GRAMSCI, 1975, Q 22, § 15, p. 2179). Assim, expressão mesmo do desenvolvimento geográfico desigual entre o Norte e o Sul da península, não é estranho que ao lado do supercosmopolitismo da "fanfarra fordista", com sua "exaltação da grande cidade", dos "planos reguladores para a grande Milão", sua "afirmação de que o capitalismo ainda está em seus inícios e que é preciso preparar-lhe os quadros de um grandioso desenvolvimento" (GRAMSCI, 1975, Q 22, $\S 2$, p. 2147), se afirme um superregionalismo, ou seja, a "conversão ao ruralismo e à desvalorização iluminista da cidade", sua "exaltação do artesanato e do patriarcalismo idílico", dos "direitos profissionais", da "luta contra a liberdade industrial" (GRAMSCI, 1975, Q 22, § 2, p. 2146-2147). Estamos claramente diante das contradições ideológicas da crise civilizacional, uma crise já imbricada à consolidação do Estado corporativo, com sua particular base social de traços meridionais. 
De fato, é preciso entender que o Estado corporativo, "exaltação do Estado em geral", do Estado "absoluto", fora forjado, nas condições italianas, a partir da contradição entre uma "base político-social" que parecia se encontrar "na "gente miúda' e nos intelectuais", e uma "estrutura" que "permanece plutocrática", tornando "impossível romper as ligações com o grande capital financeiro", já ele mesmo encarnado na figura do Estado, que se transforma em "holding das grandes massas de poupança dos pequenos capitalistas", escreveu Gramsci (GRAMSCI, 1975, Q 22, $\S 14$, p. 2177). Tudo o resultado de uma situação em que "a poupança é 'socialmente' muito cara, porque obtida com um nível de vida excessivamente baixo dos trabalhadores industriais e especialmente agrícolas" (GRAMSCI, 1975, Q 22, § 14, p. 2177).

Ou seja, enquanto o fordismo, a despeito de suas contradições, era uma resposta progressiva e racional à passagem do velho individualismo econômico à época da economia programática, o fascismo era uma resposta profundamente regressiva, uma raivosa defesa da ordem tradicional, do sistema de privilégios e da estratificação cara aos rentistas parasitas que no curso do século XIX se depositara no interior da sociedade européia (FRESU, 2015).

E eis, na leitura de Gramsci, o lugar do corporativismo no fascismo. Se para um autor como Massimo Fovel, o "corporativismo' fora a "premissa para a introdução na Itália dos mais avançados sistemas americanos no modo de produzir e trabalhar", para Gramsci, ao contrário, ele é a clara expressão "das exigências de uma polícia econômica", notadamente "agravadas pela crise de 1929" (GRAMSCI, 1975, Q 22, § 6, p. 2153-2156); vale dizer, das exigências de "repressão da conflitualidade e da liberdade de organização", da "arregimentação das estruturas organizativas, mas também, ao mesmo tempo, como reconhecimento do valor público do sindicato", embora se trate sempre de um sindicato "esvaziado e subordinado à política" (GAGLIARDI, 2009, p. 163).

Com efeito, é assim que se entende, segundo assinalou Gramsci, que

os operários qualificados italianos jamais, nem como indivíduos nem como sindicatos, nem ativamente nem passivamente, se opuseram às inovações tendentes a uma diminuição dos custos, à racionalização do trabalho, à introdução de automatismos mais perfeitos e de mais perfeitas organizações técnicas do conjunto da empresa" (GRAMSCI, 1975, Q 22, § 6, p. 2156).

A rigor, estamos diante do entendimento de que era preciso sustentar um áspero e resoluto combate a toda iniciativa, "mesmo mínima e tímida, de fazer da 
fábrica um centro de organização sindical" em prejuízo "dos sindicatos livres" (GRAMSCI, 1975, Q 22, § 6, p. 2156), como chegou a ocorrer em 1925 quando, "para obter o monopólio representativo dos trabalhadores industriais, os sindicalistas fascistas concederam à Confindustria a supressão das comissões internas", deixando com isto de pôr a questão dos "representantes de fábrica" ${ }^{5}$

De fato, já alimentado pelos mitos do passado, da "exaltação do ruralismo como exaltação da estirpe romana e italiana", funcional ao enquadramento político das massas (GIARDINA, 2008, p. 62-71), com corporativismo o fascismo leva a efeito "a remoção ou neutralização dos elementos de conflito" - da "concorrência no plano econômico", da "luta de classes no plano social", das "diferenças ideológicas no plano político" - por meio da idealização da "comuna medieval italiana", baseada "na autonomia semi-soberana das categorias" e a envolver "a transmissão por via familiar da atividade profissional", bem como "uma relação hierárquica paternalista entre o 'mestre', ou seja, o chefe da empresa, e o aprendiz, ou seja, o dependente", - que pressupõe a "imobilidade tecnológica das coletividades medievais, correspondendo, portanto, a sociedades de tipo tradicional, com níveis de produção estáticos e tendentes à auto-suficiência" (INCISA, 1997, p. 287). E é assim que se pode compreender a sua "incompatibilidade com a industrialização que, para realizar-se, exige a ruptura prévia da rígida textura corporativa, impermeável ao dinamismo produtivo e às inovações tecnológicas" (INCISA, 1997, p. 287), ou seja, sua incompatibilidade com o fordismo de traços americanos.

\section{3 - A geopolítica de um "imperialismo fraco"}

A metáfora da "nação proletária" de que falava Enrico Corradini é bem adaptada às características do imperialismo italiano, um "imperialismo fraco", como o disse Palmiro Togliatti, mas não por isso um imperialismo menos agressivo, sendo ele antes aquele que põe de modo mais urgente o problema da guerra, que é ao mesmo tempo o problema da repartição geográfica do mundo (TOGLIATTI, 2014a, p. 180). E é assim que se pode compreender a geopolítica ziguezagueante, de "manobra entre Estados e blocos de Estados rivais", que pelo menos desde o final do século XIX ocupa o Estado peninsular. Manobras que não são outra coisa senão a forma sob a qual a "essência do imperialismo" se realiza (LÊNIN, 1987, p. 90).

${ }^{5} \mathrm{O}$ exemplo é fornecido por Valentino Gerratana à página 3003 do aparato crítico que acompanha a edição crítica dos Cadernos do Cárcere que aqui estamos fazendo uso. 
E é o mesmo Togliatti que, recordando a máxima de Clausewitz ${ }^{6}$, assinala ser esta característica não mais que uma expressão "das relações de classe" que organizavam o Estado italiano, centrais na determinação das suas posições imperialistas (TOGLIATTI, 2014a, p. 180). Trata-se, também aqui, de uma crítica aos setores liberais, que tendiam a interpretar estas posições como determinadas pela "mania de grandeza" de Mussolini, ou sua "tendência insuperável a substituir o 'gesto' pelas considerações da realidade" (TOGLIATTI, 2014a, p. 178).

De fato, também Gramsci havia apontado para este caráter ziguezagueante das relações internacionais da península, produto da sua inserção subordinada na ordem geopolítica internacional, a rigor uma expressão direta da revolução passiva que guiou a unificação territorial italiana. Unificação esta que fora parte de um intricado campo geopolítico, em que contavam os interesses da Inglaterra quanto ao aparecimento de um "forte Estado italiano que pudesse substituir a Áustria na função antifrancesa no Mediterrâneo central", mas também o fato de que a península era parte da chamada "Questão oriental", que "se tinha um nó estratégico nos Balcãs e no Império turco", era já "a forma político-diplomática da luta entre Rússia e Inglaterra", ou seja, "a questão do Mediterrâneo, da Ásia próxima e central, da Índia, do Império Inglês" (GRAMSCI, 1975, Q 19, § 20, p. 2007-2008). ${ }^{7}$ Tudo o resultado da ausência de "um real impulso ao imperialismo italiano", de uma "Itália ainda imatura", que "não só não tinha capitais para exportar, mas devia recorrer ao capital externo" para as suas próprias necessidades (GRAMSCI, Q 19, § 24, p. 2019).

$\mathrm{Na}$ final do século XIX e nas primeiras décadas do século XX, a forma e o conteúdo geopolítico deste "imperialismo fraco" podem ser apreendidos a partir de pelo menos dois movimentos (TOGLIATTI, 2014a, p. 181-182).

O primeiro deles diz respeito à ruptura da Itália com o bloco da Tríplice Aliança, do qual fazia parte desde 1882. Em "1914 a Itália 'trai' os seus aliados, ÁustriaHungria e Alemanha, deixando-os sós na guerra contra a Entente", para já "em 1915 entrar em guerra contra eles" (TOGLIATTI, 2014a, p. 181-182). A burguesia italiana divisava na Entente (França, Rússia e Grã-Bretanha), insiste Togliatti, forças capazes de alcançar a vitória, e por isto se associou ao bloco em que estavam "as forças

\footnotetext{
6 "a guerra não é outra coisa senão a continuação da política de Estado por outros meios" (CLAUSEWITZ, 2014, p. XCI).

${ }^{7}$ A respeito das relações entre os Bourbons de Nápoles e o tzarismo, Gramsci escreve: no início do século XX "ainda existiam na Itália meridional cerca de 150 milhões de obrigações estatais russas, resíduos não irrelevantes da conexão que se formara entre Nápoles e a Rússia antes de 1860, contra a Inglaterra" (GRAMSCI, 1975, Q 19, § 20, p. 2008). Gramsci cita de cabeça um livro de Francesco Nitti, Il capitale straniero in Italia, que fala na verdade de 100 milhões de títulos, conforme corrigiu Gerratana no aparato crítico dos Cadernos (p. 2849).
} 
avalassadoras do imperialismo inglês", mas também porque desejava desafiar o imperialismo alemão, "que se apresentava como concorrente e adversário direto do imperialismo italiano" nos territórios em que este "havia iniciado a sua expansão", ou seja, "nos Balcãs e na Ásia Menor", pois uma guerra "ao lado da Alemanha", teria "esmagado" o imperialismo italiano, que assim seria "reduzido a uma situação de vassalo" (TOGLIATTI, 2014a, p. 182).

O segundo movimento se desenvolve no início dos anos 30. Como explica Togliatti, trata-se agora de um esforço geopolítico voltado a responder às pressões do imperialismo francês, que sufoca a Itália dominando "de modo incontrastável o Mediterrâneo ocidental", enquanto também estabelecia "uma rede de alianças que fecham o caminho à expansão italiana nas planícies do Danúbio e nos Balcãs" (TOGLIATTI, 2014a, p. 183). Além disso, a "ressurreição de um Estado nacional turco" punha de um modo novo o "problema da Ásia Menor, que não pode mais ser considerada como terra fácil de conquista por nenhum dos imperialismos" (TOGLIATTI, 2014a, p. 183). Diante destes entraves, o imperialismo italiano tendia a pôr em questão o sistema do Tratado de Versalhes. Daí a "luta para destruir a supremacia do imperialismo francês", ou seja, "pôr a questão de uma nova repartição do mundo, diversa daquela de Versalhes" (TOGLIATTI, 2014a, p. 183); cujo traçado das "fronteiras na Europa central e nos Balcãs", realizado durante a Conferência de Paz (1918), teve forte influência de Georges Clemenceau, o primeiro ministro da França e também o seu ministro da guerra, que para isso contou com "uma plêiade de geógrafos" “dirigida por Emmanuel de Martonne” (LACOSTE, 1988, p. 134). 


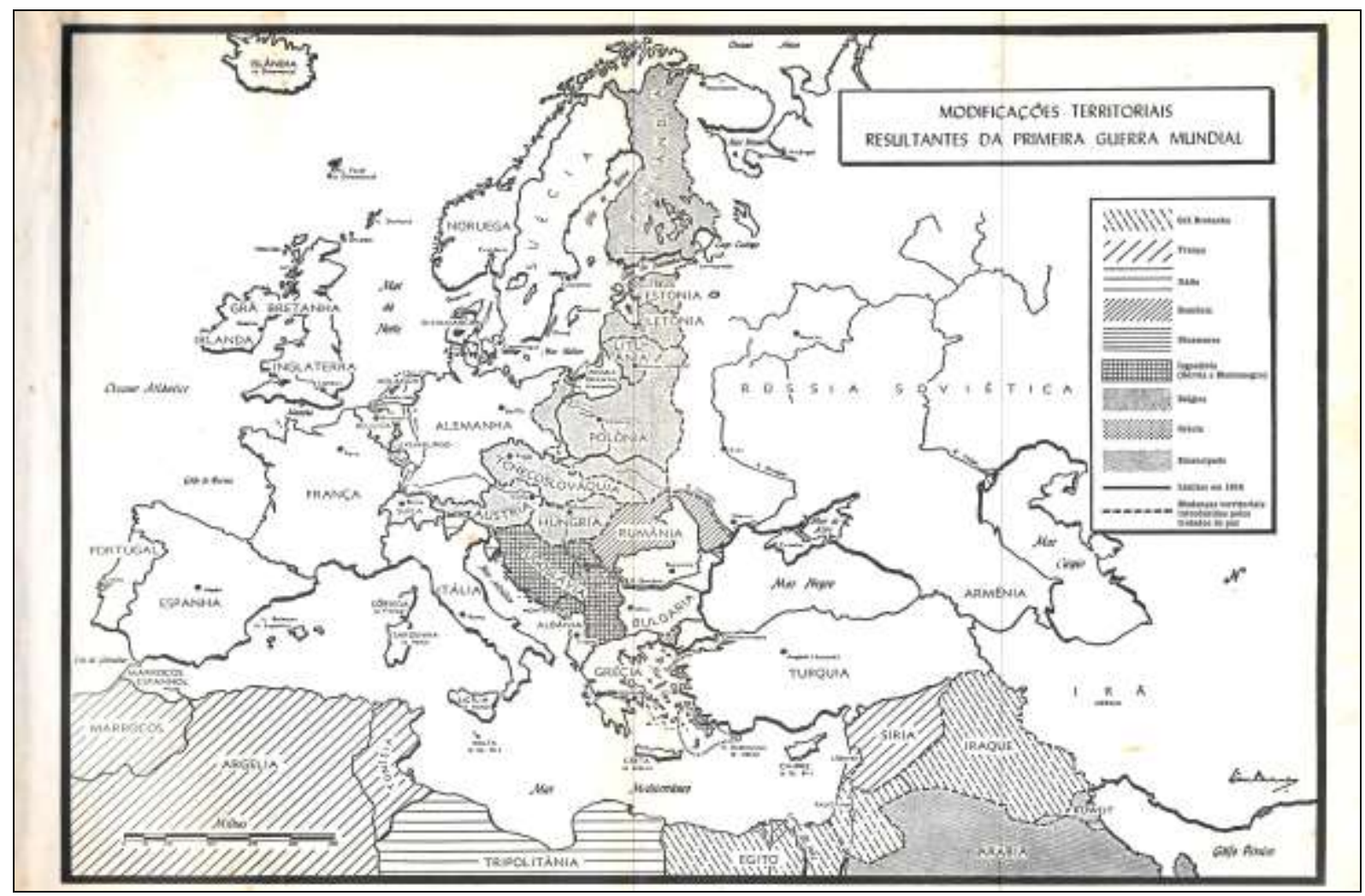

Fonte: MEDINA, Sinval F. História da Civilização. Porto Alegre: Editora Globo, 1976.

Ainda segundo Togliatti, a base "objetiva das relações entre Itália, Inglaterra e Estados Unidos" é que dava os contornos gerais a este revisionismo, uma vez que "a 'tradicional amizade inglesa' resultava do fato de que o imperialismo inglês" se comportava de modo "tradicionalmente hostil a qualquer supremacia continental", ao passo que "os Estados Unidos encontram no imperialismo italiano", um "instrumento muito cômodo para a sua luta tanto contra a França quanto contra a Inglaterra" (TOGLIATTI, 2014a, p. 183).

Certamente, o problema de enfrentar os desafios do imperialismo alemão não estava resolvido. E assim é que, depois da ascensão de Hitler, a política revisionista de Mussolini e o seu chamado à guerra "ganha um conteúdo novo", qual seja: ao impedir a "anexação da Áustria" e ao "opor a Áustria à Alemanha", Mussolini "faz uma política que é aquela tradicional dos reis da França e do Mediterrâneo francês" (TOGLIATTI, 2014a, p.186).

De fato, não surpreende mais esse outro ziguezague. Aliás, mesmo os resultados da revisão do sistema de Versalhes, já então iniciados, tendiam a não favorecer o imperialismo italiano, no exemplo da supressão das cláusulas financeiras que puseram fim às reparações de guerra impostas à Alemanha, bem como a completa revogação da "cláusula da desigualdade de direito da Alemanha frente aos ex-aliados", o que demonstra, segundo Togliatti, que as questões que o imperialismo 
italiano punha "não tinham um valor em si, mas valiam apenas como instrumento para agitar e pôr o problema bem mais geral de uma nova guerra", destinada a "uma nova divisão do mundo" (TOGLIATTI, 2014a, p. 184-185).

E é a partir desta instrumentalidade que se pode igualmente compreender porque o regime, que até o final dos anos 30 "excluíra o racismo da própria ideologia", irá esperar o contexto da conquista da Etiópia (1935-36) - que, vale notar, é também aquele que precede à II Guerra Mundial - para lançar suas leis raciais (1938): tratavase, entre outros, de "alinhar" a "política italiana à do aliado nazista" (GIARDINA, 2008, p. 66). Uma operação que tem sua expressão até mesmo no desenvolvimento da ciência da Geografia, como o demonstram as aproximações dos geógrafos italianos com a geopolítica setentrional, seja aquela do suíço Kjellen - o primeiro a usar o termo geopolítica -, como também dos alemães Ratzel e Haushofer. Estamos nos referindo a Giuseppe Dalla Vedova, seu discípulo Roberto Almagià, e sobretudo Ernesto Massi, cuja concepção de geopolítica era principalmente aquela do Lebensraum de Ratzel, tendo ele ainda traduzido Haushofer e buscado contato com Rudolf Hess, o aluno de Haushofer que foi um dos protagonistas do nacionalsocialismo, bem como se aproximado de Giuseppe Bottai, o Ministro da educação responsável por introduzir a geopolítica no ensino da Geografia durante o fascismo (AMUSQUIVAR, 2018).

Não obstante, na medida em que, do ponto de vista da obtenção do consenso, as leis raciais de Mussolini estavam fundadas no mito da "romanidade", estas sem demora entraram em aberta contradição com a "subordinação da Itália fascista à Alemanha nazista": afinal, como continuar falando, com base neste mito, em irmandade latina com a França contra a Alemanha, como se falava durante a I Primeira Guerra? (GIARDINA, 2008, p. 73). Na verdade, isto parece indicar a dificuldade do fascismo italiano de desenvolver-se nos mesmos moldes do fascismo alemão - o fascismo totalitário, como adiante veremos. $O$ que remete às origens mesmas do regime de Mussolini e do lugar que nele ocuparam os organismos da sociedade civil, em especial a forma partido, mas não menos a lgreja, já que até mesmo o "clericalismo", que na Itália nunca foi "expressão da sociedade civil", havia abandonado nos anos 20 o oportunismo da política do non expedit, isto é, o boicote parlamentar (GRAMSCI,1975, Q 19, §31, p. 2057-2058). Aliás, mesmo a burocracia estatal, responsável pelos processos de modernização, não tinha raízes no corporativismo, ou seja, não se fascistizou completamente, o que permite entender 
porque o fascismo italiano, mais que uma contrarrevolução, deva ser também ele caracterizado como uma revolução passiva (FRESU, 2015).

É, todavia, à forma partido - e notadamente pelo significado que teve enquanto organização de massa na estratégia da Resistência -, que se deve dar a máxima atenção. De fato, o Partido Fascista, como o disse Gramsci, tornar-se-ia antes de tudo uma "grande máquina parasitária", com funções mais instrumentais, de "organização do consenso", do que propriamente um "centro de exercício do poder" (FRESU, 2017, p. 83). Assim, foi no momento mesmo "da consolidação do regime", que se observou a sua máxima "marginalização", tendo ele sido basicamente reduzido a "instrumento de propaganda", o que permite concluir que no fascismo italiano, o Partido esteve sempre "subordinado ao Estado fascista, e nisto revelou uma diferença entre o padrão italiano e o alemão, onde o Estado fora já concebido como um instrumento do Partido" (FRESU, 2017, p. 83-109).

E eis como nos parece valida a conclusão de Nicola Tranfaglia, insistindo tratar-se, no caso italiano, de um "padrão débil", ou ainda "elástico de fascismo" (FRESU, 2017, p. 83).

\section{A forma totalitária alemã}

\section{1- As bases sociais e ideológicas}

Não há dúvida que entre o fascismo italiano e o nazifascismo alemão podem ser observadas claras relações de continuidade. $\mathrm{O}$ apoio das instituições tradicionais (Igreja, magistratura, burocracia) foi um claro ponto em comum, pois tanto Itália como Alemanha estiveram marcadas pela débil tradição democrática das instituições legadas pelas velhas classes agrárias parasitárias (FRESU, 2017). Ainda assim, os contextos nacionais apresentavam já diferenças importantes. Antes da ascensão do hitlerismo, a Alemanha não tinha diante de si um engenho institucional tão conservador como o Estatuto Albertino, mas as instituições da República de Weimar, apoiadas em uma das Constituições mais avançadas do entre guerras, a qual entrou em aberta contradição com a cultura autoritária das classes dirigentes assim que eclodiu a crise de 1929 (FRESU, 2017).

De fato, parecem ter sido estas contradições aquelas que levariam Togliatti a proclamar, ainda antes da ascensão de Hitler, e a despeito dos exageros que denotam a influência da teoria do social-fascismo, que o governo do chanceler Brüning (1930-32) podia "ser definido um governo que aplicava a ditadura fascista", 
enquanto "o atual governo de von Papen, embora não podendo ser considerado uma ditadura fascista completa", era já "um governo fascista, um governo que realiza a ditadura fascista com um ritmo acelerado" (TOGLIATTI, 1964, p. 74):

Ele conduz uma campanha de redução dos salários, desmobiliza o sistema de assistência social e contra a desocupação, e se esforça para cobrir esta sua política antioperária brutal com uma máscara de demagogia social que parece ser inspirada naquela de Mussolini e seus hierarcas (TOGLIATTI, 1964, p. 71). ${ }^{8}$

Outro ponto a ligar o regime de Mussolini àquele conduzido por Hitler diz respeito à base social com apoio nas camadas médias, em especial suas frações arruinadas pela crise. De fato, Hitler "se une à plebe mais embrutecida, que em plena era da industrialização nem sequer faz parte do proletariado fabril, a uma parte da população rural e sobretudo à massa pequeno-burguesa apinhada nas grandes cidades", esta última abertamente levada por sentimentos de rancor - uma marca tantas vezes referida para caracterizar o próprio Führer - e a fazer sua aparição como um grupo "que não se detém em pensamentos sobre a classe operária nem em reflexões sobre a liberdade" (KLEMPERER, 2009, p. 79-272).

É verdade que também aqui se observam diferenças dignas de nota. Se a base de apoio do fascismo italiano no campo estava nos "camponeses ricos e médios", e cujas possibilidades de maior enriquecimento "dependiam de um golpe decisivo nos operários agrícolas e nos camponeses pobres", na Alemanha a base de apoio rural do fascismo esteve claramente nos "estratos dos camponeses em via de empobrecimento, arruinados pela crise e pelos impostos, semiproletarizados" (TOGLIATTI, 1964, p. 75-6).

É este campesinato rural que o regime soube seduzir com a lei da propriedade hereditária - editada em 1933, o ano em que Hitler se torna chanceler e ainda triunfa na eleição plebiscitária de sua política econômica -, mas desde que provada a sua condição ariana, com o que esta medida torna-se um eficaz instrumento da fórmula Blut und Boden (sangue e terra), tão cara ao regime. A fórmula, que "se manteve até o final", da glorificação do "camponês apegado a terra, avesso a inovações", e "envolto em uma aura de romantismo" (KLEMPERER, 2009, p. 361). A mesma aura, vale notar, que dá sentido às cores fortemente obscurantistas $e$ irracionalistas do regime, às quais Georg Lukács, muito impressionado com a

8 Mesmo Trotsky, crítico da teoria do social-fascismo, a qual classificou como "ultra-esquerdista", referindo-se ao ano de 1928, escreveu: "Mais ou menos nessa época, a social-democracia alemã encontrava-se no poder, mostrando às massas, a cada passo, o seu papel criminoso e vergonhoso." (TROTSKY, 2018, p. 36-44) 
derrota do hegelianismo que marca o período pós-1848, associou a uma literatura da decadência e da vacuidade humana:

\begin{abstract}
O irracionalismo como concepção do mundo fixa esta vacuidade da alma humana de qualquer conteúdo social, contrapondo-a rígida e exclusivamente ao esvaziamento, igualmente mistificado, do mundo do intelecto. Assim o irracionalismo não se limita a ser a expressão filosófica da cada vez mais intensa barbarização da vida sentimental do homem, mas a promove diretamente. Paralelamente à decadência do capitalismo e à agudização das lutas de classe em decorrência da sua crise, o irracionalismo apela - sempre mais intensamente - aos piores instintos humanos, às reservas de animalidade $e$ de bestialidade que necessariamente se acumulam no homem em regime capitalista. Se as mentirosas fórmulas demagógicas do fascismo, invocadoras do 'sangue e do solo', puderam encontrar tão rápida difusão nas massas pequeno burguesas seduzidas pelo fascismo, é grande a responsabilidade que recai objetivamente sobre a filosofia e a literatura da decadência, que evocam estes instintos nos leitores e contribuem de fato para os cultivar, se bem que na maioria dos casos, não pensassem sequer longinquamente nas aplicações práticas que deles faria o fascismo, e inclusive - muito frequentemente - chegassem a rechaçá-los com indignação (LUKÁCS, 1981, p. 127).
\end{abstract}

Com efeito, pode-se assim compreender a função ideológica, de falsa consciência, deste romantismo que faz apelo ao sangue e ao solo. É ele que estará em condições de permitir a arregimentação de "inadaptados" e "arruinados". E falsa consciência também porque, um pouco à moda de um "romantismo modernizante" (PEDROSA, 2000, p. 211), era claro o flerte do regime com "o americanismo e a técnica", um meio para poder contar com "os trabalhadores da indústria", como também com as "pessoas cultas", os "professores" (KLEMPERER, 2009, p. 361 e 383). E isto não obstante o claro desdém do regime ao "pensamento sistemático", bem caracterizado na completa rejeição da "palavra filosofia", que não se "pronuncia jamais", como também as palavras System, Intelligenz, Obejektivität (KLEMPERER, 2009, p. 170-171).

Mas esta falsa consciência chega ao paroxismo com a geopolítica do regime, uma geopolítica de corte marcadamente totalitário.

\title{
2.2 - A geopolítica do fascismo totalitário
}

Em todo esse "esvaziamento do mundo do intelecto", está a centralidade do Estado-partido. Um Estado que em nenhum caso é a expressão da lei hegeliana da passagem da quantidade à qualidade, mas antes "qualquer coisa de superior aos indivíduos", um Estado "absoluto" (GRAMSCI, 1975, Q 11, § 32, p. 1446-1447). De fato, como antes dissemos, no fascismo alemão o Estado foi já concebido como um 
instrumento do partido, configurando assim a forma por excelência do fascismo "totalitário".

E eis como compreender que já a geopolítica do fascismo alemão não irá encontrar as dificuldades que se puseram diante da geopolítica italiana. Ela se funda, sem os obstáculos de uma sociedade civil, na tarefa de construção de um modelo americano de expansão colonial, o modelo de "um império territorialmente compacto na Europa centro-oriental", destinado a fornecer "escravos de raça estrangeira" e em relação aos quais a "raça dos senhores" não deveria de modo nenhum "misturar-se e confundir-se" (LOSURDO, 2014, p. 19).

O caminho ideológico percorrido por esta geopolítica é claro. Ele aparece já na germanização dos nomes das áreas anexadas nas campanhas militares, os chamados protetorados. A cidade polonesa de Lodz é transformada em Litzmannstadt; ao passo que as regiões fronteiriças recebem todas a expressão Mark: para a Áustria, Ostmark; para a Holanda, Westmark, o que deu lugar ao Atlas escolar alemão, um conjunto de mapas destinado às crianças para que conhecessem o "espaço vital da Grande Alemanha", publicado por ninguém menos que Philip Bouhler, filiado ao Partido Nazista já em 1922 e desde 1934 presidente da Comissão Oficial de Censura (KLEMPERER, 2009, p. 147-408). Uma ideologia que, a rigor, se poderia encontrar na própria Alemanha, como se sabe povoada também por eslavos, mas onde a "geografia foi purificada até os mínimos detalhes", com a germanização dos nomes de aldeias e ruas (KLEMPERER, 2009, p. 145-408).

Esta ideologia geográfica, que aparece antes de tudo como superestrutura destinada à justificação da geopolítica do III Reich, ganha os seus contornos definitivos quando se trata de reelaborar o conceito de Europa. Deve-se recordar que a "essência da ideia de Europa" presente no pensamento francês - leia-se o pensamento herdeiro do 1789 francês - "está na criação de uma determinada cultura", uma determinada postura espiritual e uma determinada vontade" (KLEMPERER, 2009, p. 252). Daí o poeta e filósofo Paul Valéry, associando-se aos que lançavam um "lamento desesperado pela autodestruição do continente durante a Primeira Guerra Mundial", ter assinalado que "o conceito de espaço europeu é uma abstração", com a Europa figurando em "todos os lugares nos quais a tríade" formada por "Grécia, Roma Antiga e Roma cristã" se faz presente, e isto "com Jerusalém incluída na Roma cristã"; mas ainda um conceito que compreenderia até mesmo a América, "uma formidável criação da Europa" ou, com mais precisão e 
para não esquecer as contradições emersas da sua "condição de potência hegemônica", do "espírito europeu" (KLEMPERER, 2009, p. 253). ${ }^{9}$

Impossível não concluir quanto ao caráter miscigenado deste conceito de Europa. Mas também, com ele, acerca da ideia de igualdade saída da Revolução Francesa, e cujo ponto alto encontramos precisamente na Revolução antiescravista e anticolonialista dos jacobinos negros do Haiti (LOSURDO, 2011, BUCK MORSS, 2013), também ela parte do contexto em que emerge o "sentido universalista" da idéia de uma "paz perpétua", teorizada por Kant (LOSURDO, 2008, p. 11-13).

De fato, esta concepção está ainda além de qualquer "coloração estritamente latina" e "sua orientação exclusivamente ocidental" (KLEMPERER, 2009, p. 255). Valer dizer, além de qualquer "abordagem essencialista" (o essencialismo dos povos), às vezes cara, mesmo, a uma parte da esquerda, como lembrou a crítica de Domenico Losurdo (2017, p. 103). ${ }^{10}$ Com efeito, desde "que os textos de Tolstoi e de Dostoievski passaram a exercer influência na Europa", e "desde que o marxismo se tornou marxismo-leninismo" e "se vinculou à técnica norte-americana, o centro de gravidade do pensamento europeu se deslocou para Moscou" (KLEMPERER, 2009, p. 255). Ou seja, mais que qualquer outra, é de filosofia da história, e mais precisamente da filosofia da história que se reconhece herdeira da filosofia clássica alemã, que se está falando para definir este conceito de Europa, a toda prova universalista.

E é assim que "o conceito de Europa sofre um estranho retrocesso" nas mãos do aparelho de propaganda do Reich hitleriano. Para o fascismo alemão, tudo o "que fosse europeu procedia dos nórdicos, ou dos germano-nórdicos, e todo elemento danoso ou ameaçador provinha da Síria e da Palestina" (KLEMPERER, 2009, p. 253-254). A Europa, enfim, deveria "ser entendida em um sentido exclusivamente espacial e material", designando um "território mais restrito"; ela "termina onde começa a Rússia inimiga, cujo território, em grande parte, a Alemanha reivindica, considerando-o ilegítimo"; mas igualmente uma Europa que "se separou da GrãBretanha, adotando em relação a ela uma atitude de defesa hostil" (KLEMPERER, 2009, p. 255-256). E assim entende-se por que, na filologia abertamente ideológica do Terceiro Reich, mais 'freqüente do que o substantivo 'judeu' é o adjetivo

9 "Expresso-me mal, não é a Europa que domina, mas sim o europäischer Geist [espírito europeu]" (KLEMPERER, 2009, p. 253).

10 Losurdo refere-se à categoria de "totalistarismo oriental", utilizada por autores tão distantes no tempo como Kautsky, Marcuse, Horkheimer, Žižek, os quais, remetendo mais à "essência oriental do que à história e à geografia", põem-se a condenar as experiências do socialismo real (LOSURDO, 2017, p. 103-104). 
'judaico". É ele "que reduz todos os adversários a um único inimigo", permitindo falar do "sistema de exploração judaico-capitalista", do "interesse dos grupos judaicoingleses e judaico-americanos na destruição da Alemanha", mas sobretudo da "visão do mundo judaico-marxista" e da "barbárie judaico-bolchevista" (KLEMPERER, 2009, p. 275). Esta última, deve-se notar, uma categoria já utilizada pelo teórico racista norte-americano Lothrop Stoddard, o primeiro a cunhar o termo sub-homem nos EUA - The menace of the Under Man é o subtítulo do seu livro de 1923 - e para quem os judeus ocupavam uma "posição eminente" no "corpo dos oficiais" da revolta "bolchevique e anticolonial" (LOSURDO, 2017, p. 114).

Não há dúvida, estamos diante do terrível projeto dedicado a "germanizar o solo sem nunca germanizar os homens", e que toma como inspiração o projeto seguido do outro lado do Atlântico já pelos Estados Unidos, que se "expandiu a Oeste americanizando o solo, não os pele vermelhas", destinados ao extermínio e à escravização (LOSURDO, 2014, p. 23). São relações negligenciadas nas análises de Lukács e Klemperer, mas muito claras e fazendo-se sentir, pelo menos desde 0 final do século XIX, já em muitas partes da Europa. Com efeito, deve-se recordar que a teoria da eugenia de Francis Galton, o primo de Darwin conhecido e citado "com louvor" por Nietzsche, também ele defensor da "castração" dos delinquentes, encontra "grande sucesso" nos EUA, país que logo "se distingue na realização prática das medidas desta nova 'ciência"” (LOSURDO, 2016, p. 76-77) 11.

Mas a categoria dos sub-homens (o Under Man americano, Untermesch em tradução alemã), como se viu, inclui agora também e principalmente as inclinações políticas e ideológicas. Estamos, sim, aqui, inteiramente diante da categoria de totalitarismo, tal como a definiu Losurdo, insistindo ser ela, já há muito tempo e em especial entre os povos coloniais, aquela que demarca o nexo entre Terceiro Reich, colonialismo e racismo (LOSURDO, 2017, p. 105).

\section{À guisa de conclusão: a luta da Resistência e a queda do fascismo}

São belas as páginas da derrota imposta ao nazisfascismo pelas forças da resistência. A rigor, trata-se de um processo marcado por uma dialética geográfica, em que as forças da resistência antifascista do Ocidente se alimentavam e mesmo auxiliavam a frente do Leste liderada pela URSS. A rigor, uma vitória organizada a

11 "Sob a força de um movimento já desenvolvido no fim dos 1800, entre 1907 e 1915 treze estados americanos promulgam leis para a esterilização coercitiva, a quem devem ser sujeitados... 'delinquentes habituais, idiotas, imbecis e abusadores'” (LOSURDO, 2016, p. 77). 
partir de uma política de frente única que, pelo menos desde 1935, a IC pensava já como uma política que deveria operar por baixo, através da aliança com os socialdemocratas, mas também por cima, isto é, com os chefes da socialdemocracia (GIACOMINI, 2004).

De fato, foi a partir da vitória da frente Leste em Stalingrado que o curso da II Guerra mudou radicalmente, renovando as esperanças e a capacidade de luta na frente ocidental. Basta recordar que após esta batalha, os trabalhadores italianos se infundiram de coragem e em 5 de março de 1943 deflagraram uma greve na fábrica da Fiat de Turim, ao passo que no dia 23 do mesmo mês, milhares de operários se recusaram a trabalhar em Milão, organizando agitações que logo assumiram palavras de ordem antifascistas, contexto em que a rede organizativa do PCI logo conseguiu estender-se através de inúmeros comitês unitários de ação (FRESU, 2017).

Como demonstrou Fresu (2017), a luta antifascista não pode também ser bem compreendida sem o conhecimento das reflexões de Gramsci. Toda a luta de libertação e o próprio papel que aí cumpriu o $\mathrm{PCl}$ se desenvolveram em estreita relação com as reflexões do comunista sardo. Um fato, aliás, a pôr em questão as teses que buscam estabelecer uma descontinuidade entre as fases pré e póscarcerária dos textos de Gramsci, e isto a despeito da universalidade do seu aporte categorial - sempre a ser lido pelo critério da tradutibilidade, de modo a evitar "abstracionismos mecanicistas" (GRAMSCI, 1975, Q 11, § 48, p. 1469).

São ilustrativos, nesse sentido, os desenvolvimentos que se seguiram ao caso do deputado Giacomo Matteoti, dirigente do Partido Socialista que, ao denunciar as fraudes e a violência que envolveu a vitória de Mussolini nas eleições de 1924, foi barbaramente assassinado pelo regime (junho de 1926). Acompanhemos o relato de Fresu (2017). Diante da ampla reação das camadas médias e até mesmo das direções do mundo industrial e bancário, o PCl lança a proposta de uma greve geral e de um parlamento alternativo, proposta todavia não aceita pelo conjunto dos liberais e católicos, interessados em uma oposição apenas moral ao fascismo. Foi a desmobilização das massas daí resultante que permitiu que Mussolini abrisse uma segunda fase do regime, instalando a partir de outubro de 1926 uma ditadura propriamente dita, que pôs na ilegalidade todos os seus adversários.

E é no clima de crescente tensão sucessivo ao assassinato de Matteoti que se realiza, no $\mathrm{PCl}$, o famoso Congresso de Lyon (janeiro de 1926), opondo as linhas de Amadeo Bordiga e Antonio Gramsci, com desfecho vitorioso para o grupo de Gramsci. 
Segundo Fresu (2017), a corrente bordiguiana nada tinha a oferecer à Resistência que se organiza a partir dos anos 30 . Prendendo-se às teses dominantes no interior da IC, como vimos sustentadas sobretudo por Thälmann, ela se inclinava a apontar o reformismo, e não o fascismo, como o inimigo a derrotar, incluindo o que chamava de "fascismo intermediário", um agrupamento de constitucionalistas, democratas e também sociais-democratas. Já a corrente de Gramsci, valorizando o debate em torno das frentes únicas, realizado no III e IV Congressos da IC (respectivamente em 1921 e 1922), abria-se para a idéia leniniana da NEP (Nova Política Econômica). Vale dizer, a ideia das alianças e da questão camponesa como uma questão estratégica e, a partir daí, da necessidade de "nacionalizar" a revolução, uma vez alcançada a conclusão acerca da "complexidade" e do "longo prazo" de sua realização em escala mundial, o que implicava em "concessões até onerosas a estratos sociais burgueses" e, assim também, um distanciamento da teoria da revolução permanente de Trotsky, considerada "uma 'forma moderna do velho mecanicismo"' (LOSURDO, 2006, p. 158161). A rigor, e sobretudo se se pensa nas experiências da social-democracia no Ocidente, também um meio de evitar a negligência das diferenças entre quadro democrático e reacionário, ou fascista (FRESU, 2017), mas igualmente um modo de encontrar aplicação, no Ocidente, para a lição leninista acerca do nexo entre questão social e questão nacional, bem compreendida entre os comunistas que viviam na Alemanha do início dos anos 20 apenas por Karl Radek (AZZARÀ, 2017).

Vitoriosa em Lyon, a nova posição do $\mathrm{PCl}$ foi crucial para a mudança de avaliação na própria IC a partir de 1934, tendo Palmiro Togliatti aí desempenhado um papel importante, embora mesmo ele, como vimos, tivesse sustentado a tese do social-fascismo - uma posição compreensível à luz do contexto de isolamento geopolítico da União Soviética, que se viu diante da reaproximação entre França e Alemanha em 1925, do golpe de Estado na Polônia que no mesmo ano marcou a ascensão do fascista Pilsudki, e ainda da ruptura das relações diplomáticas e comercias com a Grã-Bretanha, ocorrida em 1927 (LOSURDO, 2010, p. 135-136).

$\mathrm{Na}$ verdade, já o artigo escrito como crítica a Trotsky que antes citamos, embora ainda redigido à luz da tese do social-fascismo, ensaiava a política do novo período (TOGLIATTI, 1964). De fato, como assinalou Fresu (2017), reaproximando-se da linha sustentada por outros dirigentes, Gramsci entre eles, é Togliatti quem irá abrir críticas à IC no que respeita à ausência de uma política para atrair a pequena burguesia rural e urbana, e ainda da negligência quanto à importância de defender as liberdades democráticas nas nações livres e nos países fascistizados. E é neste 
sentido, que na Itália ainda dominada por Mussolini, o dirigente comunista irá sustentar a inserção nos sindicatos fascistas. Tratava-se de um caminho para fazer avançar a luta de massas, propunha Togliatti, impondo-se com ele até mesmo a tarefa de investigar a nova política econômica do regime, encaminhada em 1927 com a Carta del Lavoro e o corporativismo, elementos, dadas as suas exigências de uma base de massa e de consenso passivo - os elos consensuais da conexão coerção e consenso, recordemos -, a distingui-lo dos tradicionais regimes ditatoriais (FRESU, 2017). Nas palavras de Togliatti, que assim buscava aconselhar o Partido Comunista da Alemanha:

Aprendam, desde os primeiros momentos, a desenvolver um trabalho de massa nas organizações adversárias, estudem a fundo as formas, os métodos deste trabalho. Nós pagamos muito duramente o fato de não ter aprendido a tempo esta lição desde os primeiros tempos do fascismo. Se tivéssemos aprendido a tempo esta lição talvez não nos encontraríamos hoje em uma situação de ilegalidade assim tão rigorosa, assim tão sufocante, teríamos encontrado mais cedo e melhor a via do contato com as grandes massas, não teríamos nunca perdido este contato (TOGLIATTI, 1964, p. 82).

Aí estão descritas as raízes da política de frente única, capaz de reunir comunistas, socialistas, republicanos e até mesmo ex-fascistas. Uma política já experimentada na Espanha e em condições de forjar um novo caminho para o socialismo, e do qual esteve consciente mesmo Stalin (CANFORA, 1998). Frente única experimentada nas mais de 500 formações dos partigiani que, ao fim da guerra, e diante da lentidão das forças aliadas, tomaram em suas próprias mãos a tarefa de liquidar os restos dos regimes fascistas, conformando uma estrutura unitária que correspondia ao grande bloco democrata e nacional dos partidos antifascistas, ao qual deveriam integrar-se os comunistas italianos (FRESU, 2017). A rigor, uma expressão mesmo da formação social em que se desenvolvera o fascismo na Itália, sua forma débil ou elástica.

É verdade que este processo não logrou levar adiante o desenvolvimento de uma nova formação socialista. Desenvolvimento para o qual se empenhou a teorização do próprio Togliatti, que se abrindo para a ideia da revolução como "um processo", buscou pôr em relação, no pós-II Guerra, e a partir da constatação de que "as situações revolucionárias agudas não surgem com muita freqüência", a luta por reformas "econômicas" e "políticas" e "a luta para superar o regime capitalista", uma relação que o "reformismo tende a esquecer" (CANFORA, 1998, p. 41-44), a rigor desinteressado de uma "válida e profunda reforma das estruturas" (TOGLIATTI, 2014b, p. 915). Não obstante, foi certamente através das lutas que partiram deste 
bloco - não tão forte nas formações onde a liberação foi principalmente um resultado da ação das forças aliadas -, e onde o PCl teve um papel destacado, que se logrou dar forma à construção de uma forte democracia social no período pós-1948. Uma democracia que, sem desprezar a luta parlamentar, mas não reduzida a ela, posto já enraizada na luta popular da Resistência, encaminha a superação das limitações do Estatuto Albertino por meio de uma síntese pós-liberal entre as concepções formal e substancial de justiça, respectivamente fundadas na igualdade dos cidadãos perante a lei e na busca da superação das profundas diferenças econômicas e sociais da península (FRESU, 2017). Um equilíbrio tal das relações de forças em luta que, expressão da clara progressividade histórica que este processo encerrou, a Constituição que daí emergiu é hoje considerada um verdadeiro "monumento à luta das classes subalternas na Itália" (AZZARÀ, 2017, p. 77).

\section{Referências bibliográficas}

AMUSQUIVAR, Érica L. Antonio Gramsci e a geopolítica: teoria e história. 2018 $188 f$ Tese (Doutorado em Ciência Política) - Programa de Pós-Graduação em Ciência Política - IFCH, Universidade Estadual de Campinas, São Paulo, Brasil, 2018.

AZZARÀ, Stefano G. Globalisti contro sovranisti: un conflito tutto interno alle classi dominanti. In: II bene comune, mar. 2017.

BUCK MORSS, Susan. Hegel, Haití y la Historia Universal. Trad. J. M. Espinosa. México: FCE, 2013.

CANFORA, Luciano. Un ribelle in cerca di libertà: profilo di Palmiro Togliatti. Palermo: Sallerio, 1998.

CLAUSEWITZ, Carl Von. Três notas de Clausewitz sobre Da guerra. In: Clausewitz, Carl von. Da Guerra. São Paulo: Martins Fontes, 2014.

FRESU, Gianni. Traducibilità e modernità del nesso concettuale egemonico/subalterno nelle relazioni di Peter Thomas e Cosimo Zene. In: International Gramsci Journal, no 4 (2nd Series/2ª Serie), June/Giugno, 2015.

FRESU, Gianni. Nas trincheiras do Ocidente. Lições sobre fascismo e antifascismo. Ponta Grossa: UEPG, 2017.

GIARDINA, Andrea. O mito fascista da romanidade. In: Estudos Avançados, $n^{\circ} 62$, 2008.

GAGLIARDI, Alessio. Corporativismo. In: Dizionario gramsciano - 1926-1937. Liguori, G. e Voza, P. (Orgs.).Roma: Carocci, 2009. 
GIACOMINI, Ruggero. Stalin 'segreto': dal Diario di Dimitrov. In: Stalin nella storia del novecento. Milano: Teti Editore, 2004.

GIACOMINI, Ruggero. II giudici e il prigioniero. Roma: Castelvecchi, 2014.

GRAMSCI, Antonio. Quaderni del Carcere. Edizione crítica dell"Istituto Gramsci a cura de Valentino Gerratana. Torino: Einaudi, 1975.

INCISA, Ludovico. Corporativismo. In: Norberto Bobbio, Nicola Matteucci, e Gianfranco Pasquino, G (orgs.). Dicionário de Política. 10ª ed., vol.1. Tradução João Ferreira, revisão da tradução João Ferreira e Luis Guerreiro Pinto Cacais. Brasília: editora da UNB, 1997.

KLEMPERER, Victor. A linguagem do Terceiro Reich. Tradução Miriam Bettina Paulina Oelsner. Rio de Janeiro: Contraponto, 2009.

LACOSTE, Yves. A Geografia: isso serve antes de mais nada para fazer a guerra. Trad. M. C. França. São Paulo Papirus, 1988.

LÊNIN, Vladimir I. Imperialismo, fase superior do capitalismo. São Paulo: Global, 1987.

LOSURDO, Domenico. II revisionismo storico: problemi e miti. Roma: Laterza, 1998.

LOSURDO, Domenico. Gramsci, do liberalismo ao comunismo crítico. Tradução Teresa Ottoni; revisão da tradução Giovanni Semeraro. Rio de Janeiro: Revan, 2006.

LOSURDO, Domenico. A Revolução, a nação e a paz. Tradução Paulo Butti de Lima. In: Estudos Avançados, vol 22, nº 62, jan-abr. 2008.

LOSURDO, Domenico. Stalin: história crítica de uma lenda negra. Tradução Jaime A. Clasen. Rio de Janeiro: Revan, 2010.

LOSURDO, Domenico. Hegel e la libertà dei moderni. Vol 2. Napoli(It): La scuola di Pitagora, 2011.

LOSURDO, Domenico. Stalin e Hitler: fratelli gemelli o nemici mortali?. In: Historia Magistra. Rivista di Sotia Critica, № 15, 2014.

LOSURDO, Domenico. Nietzsche e a crítica da Modernidade. Tradução de Alessandra Siedschlag. São Paulo: Ideias e Letras, 2016.

LOSURDO, Domenico. II marxismo occidentale. Come nacque, come morì, como può rinascere. Roma: Laterza, 2017.

LUKÁCS, Georg. A decadência ideológica e as condições gerais da pesquisa científica. In: Lukács - sociologia. Netto, J. P. e Coutinho, C. N. (Orgs.). São Paulo: Ática, 1981.

MEDINA, Sinval F. História da Civilização. Porto Alegre: Editora Globo, 1976. 
PEDROSA, Mário. Futurismo, romantismo modernizante. In: Modernidade cá e lá: textos escolhidos. Vol 4. Arantes, Otilia (org.). São Paulo: Edusp, 2000.

ROBERT MORAES, Antônio C. A antropogeografia de Ratzel. In: Ratzel - Geografia. Moraes, A. C. R. (Org.). São Paulo: Ática, 1991. (Coleção Grandes Cientistas Sociais).

TOGLIATTI, Palmiro. Contro le false analogie tra situazione tedesca e situazione italiana. In: Sul movimento operario internazionale. Roma: Riuniti, 1964.

TOGLIATTI, Palmiro. Per comprendere la politica estera del fascismo italiano. In: La politica nel pensiero e nall'azione. Scritti e discorsi 1917-1964, Michele Ciliberto e Giuseppe Vacca (orgs.). Bompiani: Milano, 2014a.

TOGLIATTI, Palmiro. Capitalismo e riforme di struttura. In: : La politica nel pensiero e nall'azione. Scritti e discorsi 1917-1964, Michele Ciliberto e Giuseppe Vacca (orgs.). Bompiani: Milano, 2014b.

TROTSKY, Leon. O giro da Internacional Comunista e a Situação Alemã. In: Como esmagar o fascismo. Tradução Aldo Sauda e Mario Pedrosa. São Paulo: Autonomia Literária, 2018.

\section{Notas de Autor}

CONTRIBUIÇÃO DE AUTORIA

Marcos Aurélio da Silva - Concepção. Elaboração do manuscrito, revisão e aprovação da versão final do trabalho.

\section{FINANCIAMENTO}

Não se aplica.

CONSENTIMENTO DE USO DE IMAGEM

Não se aplica.

APROVAÇÃO DE COMITÊ DE ÉTICA EM PESQUISA

Não se aplica.

\section{CONFLITO DE INTERESSES}

Não se aplica.

\section{LICENCCA DE USO}

Este artigo está licenciado sob a Licença Creative Commons CC-BY. Com essa licença você pode compartilhar, adaptar, criar para qualquer fim, desde que atribua a autoria da obra.

\section{HISTÓRICO}

Recebido em: 23-06-2019

Aprovado em: 23-11-2019 